\title{
Intrauterine Progestin Therapy as a New Approach to Premalignant Endometrial Polyps: A Prospective Observational Study
}

\author{
ELISE THORESEN SLETTEN ${ }^{1,2,3}$, MARIT ARNES ${ }^{2}$, ANNE BEATE VEREIDE ${ }^{1,3}$ and ANNE ØRBO $^{2}$ \\ ${ }^{1}$ Department of Gynecologic Oncology, Clinic for Surgery, Cancer and Women's Diseases, \\ University Hospital of North Norway, Troms $\phi$, Norway; \\ ${ }^{2}$ Research Group for Gynecologic Oncology, Department of Medical Biology (IMB), \\ Faculty of Health Sciences, University of Troms $\phi$, Troms $\phi$, Norway; \\ ${ }^{3}$ Department of Clinical Medicine (IKM), Faculty of Health Sciences, University of Troms $\phi$, Troms $\phi$, Norway
}

\begin{abstract}
Background/Aim: Endometrial hyperplastic polyps (EHP) may progress to endometrial carcinoma (EC) if left untreated. We aimed to prospectively investigate the efficacy of the low-dose levonorgestrel intrauterine system (LNG-IUS) as therapy for EHP with malignant potential. Patients and Methods: In total, 37 women with EHP underwent therapy with LNG-IUS containing $13.5 \mathrm{mg}$ levonorgestrel for six months or 4-10 weeks depending on whether the EHP was characterized (by D-score analysis) as low- to medium-risk $(n=33)$ or high-risk $(n=4)$ of coexistent or future EC. Therapy response was defined as complete clearance of hyperplastic glands in post-therapy endometrial biopsy. Results: All women with low- to medium-risk EHP obtained therapy response, whereas only 1 out of 4 with highrisk EHP responded to therapy. None of the women were diagnosed with EC during the study and no serious adverse events occurred. Conclusion: Low-dose LNG-IUS represents a promising therapy for selected women with EHP.
\end{abstract}

Endometrial polyps (EP) frequently occur in pre, peri and postmenopausal women and may be diagnosed in $20-30 \%$ of patients with abnormal uterine bleeding (1). Although most EP are benign, a systematic review has reported premalignant (hyperplastic) and malignant changes to be present in 0.2$23.8 \%$ and $0-12.9 \%$ of the cases, respectively (2).

This article is freely accessible online.

Correspondence to: Professor Emerita Anne Ørbo, Research Group for Gynecologic Oncology, Department of Medical Biology, Faculty of Health Sciences, University of Troms $\varnothing$, N-9037 Troms $\varnothing$, Norway. Tel: +47 99530372, e-mail: anne.orbo@uit.no

Key Words: Endometrial polyps, LNG-IUS, progestin therapy.
Previous research has mainly focused on the oncogenic potential of macroscopically visible polyps, related to clinical characteristics such as polyp size, symptoms, use of hormonal medication, patient's age, BMI and menopausal status, and whether such polyps should be hysteroscopically resected or not $(3,4)$. More recently, the coexistence of hyperplastic endometrial polyps (EHP) with endometrial hyperplasia (EH) and endometrial carcinoma (EC) in the surrounding nonpolypoid endometrium, has gained increasing attention $(5,6)$.

Despite the fact that management of malignant EP now coincides with current therapy recommendations for EC, no therapy guidelines are available when EHP are detected in endometrial biopsies or polypectomy specimens. However, the described tendency of EHP to coexist with multifocal hyperplastic lesions in the non-polypoid endometrium and the suggested causal connection between polyp formation with and unopposed estrogen stimulation of the endometrium indicates a potential role for hormonal therapy with progestin in these women.

The pathogenesis of EP is not fully understood. In contrast, it is well established that non-polypoid EH is an estrogendependent precursor lesion to EC with up to $30 \%$ risk of malignant progression (7). Oral and intrauterine progestin has been routinely and successfully used as treatment for this condition since decades and randomized trials have shown higher regression rates for intrauterine compared to oral progestin therapy in patients with non-atypical EH (8-11).

So far, progestin therapy is poorly investigated in patients with EP and EHP although such studies have been requested $(12,13)$. A Cochrane review concluded that the LNG-IUS has a preventive effect and reduces the incidence of benign polyp formation in women undergoing tamoxifen therapy for breast cancer (14). A former retrospective observational study demonstrated that all women diagnosed with low- to mediumrisk EHP were cured after six months treatment by the high- 
dose LNG-IUS (Mirena ${ }^{\circledR}, 52 \mathrm{mg}$, Bayer Pharmaceuticals, Berlin, Germany), independent of diagnosis (simple, complex, or atypical hyperplasia), whereas only $25 \%$ of patients receiving oral progestin obtained response (15). Sustained regression of EHP for as long as the LNG-IUS (FibroPlant ${ }^{\circledR}$ APCOR Research, Ghent, Belgium) remained in situ was described in a single case report by Janssen et al. (16).

In a recent study, low-dose LNG-IUS (Jaydess ${ }^{\circledR}$, Bayer Pharmaceuticals, Berlin, Germany), with a total content of 13.5 $\mathrm{mg}$ levonorgestrel, was successfully given as therapy for six months in women with low- and medium-risk EH (17). Compared to the high-dose LNG-IUS, the thinner insertion tube and smaller T-frame might prove beneficial for young nulliparous women and for elderly women with stenotic cervical channel simultaneously reducing systemic side-effects to a minimum. Thus, the main objective of the current pilot study was, as the first ever, to investigate if the low-dose LNG-IUS is sufficient therapy for EHP with various malignant potential.

\section{Patients and Methods}

The study was designed as a prospective, multicenter, pilot study to assess the efficacy of low-dose LNG-IUS as therapy for EHP. LNGIUS $13.5 \mathrm{mg}$ is approved as a contraceptive for up to three years use (18). The in vivo LNG-release rate declines progressively after insertion (19). After 24 days, 60 days and 3 years the LNG release rate was calculated to be $14 \mu \mathrm{g} / 24 \mathrm{~h}, 10 \mu \mathrm{g} / 24 \mathrm{~h}$ and $5 \mu \mathrm{g} / 24 \mathrm{~h}$, respectively. Average LNG release rate over three years was $6 \mu \mathrm{g} / 24 \mathrm{~h}$ (19). Preand post-menopausal women with histologically confirmed EHP were eligible for study inclusion. Histopathological material (baseline biopsy) from the endometrium, obtained prior to study inclusion, was sampled by Pipelle (Pipelle, Laboratoire CCD, Paris, France) $(n=22), D \& C$ (dilatation and curettage) $(\mathrm{n}=10)$, or hysteroscopic transcervical resection $(n=6)$. All women had consulted their gynecologists due to abnormal uterine bleeding, and were diagnosed with menometrorrhagia $(n=20)$, menorrhagia $(n=5)$, or postmenopausal bleeding $(n=13)$. Endometrial thickness, measured by transvaginal ultrasound prior to therapy, varied from 3 to $30 \mathrm{~mm}$.

Enrollment. The study was open for inclusion from August 1st, 2015 to August 1st, 2017. A total of 38 women were consecutively recruited to the study at six different gynecological outpatient clinics in northern Norway between December 8th, 2015 and July 17th, 2017. Written informed consent was obtained from all participants. The LNG-IUS was inserted by the responsible gynecologist in accordance to manufacturer's instructions. Blood samples were obtained at inclusion to measure s-estradiol and s-FSH. According to our laboratory practice, these values can be used to define menopausal status.

Study participants were assigned to two different therapy groups according to individual risk stratification, based on WHO94 classification and D-score (see Morphometric analysis (D-score)) in baseline biopsy, concerning the probability of coexistent or future EC. Women with low- to medium-risk hyperplastic polyps (simple hyperplasia $(\mathrm{SH})$ or complex hyperplasia $(\mathrm{CH})$ and a D-score $\geq 0$ ) received conservative therapy with low-dose LNG-IUS for six months (therapy group A). Women with high-risk hyperplastic polyps $(\mathrm{CH}$ or atypical hyperplasia $(\mathrm{AH})$ and a $\mathrm{D}$-score $<0)$ were scheduled for hysterectomy and underwent therapy with low-dose LNG-IUS for 4-10 weeks while awaiting surgery (therapy group B). CT scan of the chest, abdomen and pelvis and a pelvic MRI scan were performed in all women in therapy group B to exclude signs of EC (endometrial tumor, myometrial invasion, pathological lymph nodes, or presence of metastases).

Therapy was completed at 29th of November 2017. After completing the study, further therapy and surveillance were individualized and left to the patient's gynecologist to decide. Women in therapy group A were encouraged to keep the low-dose LNG-IUS in situ after the end of study period if side effects were acceptable, to provide long-term endometrial protection. No deviations from the study protocol occurred.

Outcome measures. The primary outcome of interest was endometrial tissue response assessed by light microscopy of repeat biopsy specimens. As quality evidence of different sampling methods during progestin therapy is lacking, feasibility in outpatient practice and consideration of cost perspective led to our choice of Pipelle as sampling method for obtaining post-therapy biopsy material in therapy group A. In group B, therapy response was evaluated by histopathological examination of the hysterectomy specimen.

For therapy group B, hysterectomy was performed after 4-10 weeks and post-therapy evaluation was based on standard histopathological examination of the hysterectomy specimen. Endometrium with progestin effect (atrophic glands and pseudodecidualized stroma) was defined as therapy response for both patient groups. Presence or absence of polyps or fragments of polyps were also evaluated. Secondary outcome was adverse events during therapy.

Histological specimens. The histopathological material (baseline biopsies, post-therapy biopsies and hysterectomy specimens) was received at the Department of Pathology, University Hospital of North Norway for routine assessment. All biopsies were fixed in buffered formaldehyde and further processed in the laboratory to prepare standard histological sections. Microscopic assessment was performed by a trained gynecologic pathologist (AO) and one additional routine pathologist. EP diagnosis was made when microscopy revealed polyps or fragments of polyps, identified by the characteristic shape covered by surface epithelium, and/or by fibrous stroma with thick-walled or enlarged vessels (20). In the present study the diameter of polyps or fragments was $>5 \mathrm{~mm}$ and $<12 \mathrm{~mm}$. Hyperplastic areas within the polyps were diagnosed according to WHO94 classification using one of the three terms: $\mathrm{SH}, \mathrm{CH}$, or $\mathrm{AH}$, which was still considered the gold standard for evaluating EH when the study was planned and formally approved $(7,21)$. Ordinary light microscopy was always followed by D-score analysis (see Morphometric analysis (D-score)). Hysterectomy specimens from patients in therapy group B were also sent to the Department of Pathology, University Hospital of North Norway, for routine examination. The entire endometrium was embedded in paraffin blocks and evaluated for the presence of EH, EHP or EC.

Morphometric analysis (D-score). Because reproducibility of the different classification systems for the diagnosis of EH performed by light microscopy is still debated, the morphometric image analysis algorithm (D-score) has been introduced in the national routine recommendations in Norway to improve the selection of risk groups for hyperplastic lesions. Thus, hyperplastic lesions with Dscore $\geq 0$ are considered to be of low- to medium-risk and lesions 
Table I. Clinical and demographic patient characteristics of the study cohort, $n=37$.

\begin{tabular}{|c|c|c|}
\hline Characteristics & $\mathrm{n}$ & $(\%)$ \\
\hline \multicolumn{3}{|l|}{ Age (years) } \\
\hline$<45$ & 9 & 24.3 \\
\hline $45-55$ & 20 & 54.1 \\
\hline$>55$ & 8 & 21.6 \\
\hline \multicolumn{3}{|l|}{ BMI $\left(\mathrm{kg} / \mathrm{m}^{2}\right)$} \\
\hline Normal Weight $(<25)$ & 8 & 21.6 \\
\hline Overweight (25-29.9) & 16 & 43.2 \\
\hline Obese $(\geq 30)$ & 13 & 35.1 \\
\hline \multicolumn{3}{|l|}{ Estradiol level (nmol/l) } \\
\hline$<0.12$ & 15 & 40.5 \\
\hline $0.12-0.26$ & 6 & 16.2 \\
\hline$\geq 0.27$ & 16 & 43.2 \\
\hline \multicolumn{3}{|l|}{ Menopausal status* } \\
\hline Premenopausal & 20 & 54.1 \\
\hline Perimenopausal & 2 & 5.4 \\
\hline Postmenopausal & 15 & 40.5 \\
\hline \multicolumn{3}{|l|}{ Vaginal bleeding } \\
\hline Menometrorrhagia & 20 & 54.1 \\
\hline Menorrhagia & 4 & 10.8 \\
\hline Postmenopausal bleeding & 13 & 35.1 \\
\hline \multicolumn{3}{|l|}{ Parity } \\
\hline 0 & 5 & 13.5 \\
\hline $1-2$ & 13 & 35.1 \\
\hline $3-4$ & 18 & 47.6 \\
\hline$>4$ & 1 & 2.7 \\
\hline \multicolumn{3}{|l|}{ Method of diagnosis } \\
\hline Pipelle & 22 & 59.5 \\
\hline $\mathrm{D} \& \mathrm{C}$ & 9 & 24.3 \\
\hline Hysteroscopic resection & 6 & 16.2 \\
\hline \multicolumn{3}{|l|}{ WHO94 diagnosis } \\
\hline $\mathrm{SH}$ & 14 & 37.8 \\
\hline $\mathrm{CH}$ & 20 & 54.1 \\
\hline $\mathrm{AH}$ & 3 & 8.1 \\
\hline \multicolumn{3}{|l|}{ D-score category } \\
\hline$<0$ & 4 & 10.8 \\
\hline$\geq 0$ & 33 & 89.2 \\
\hline
\end{tabular}

*Menopausal status was defined by serum levels of estradiol (nmol/l) and follicle stimulating hormone (FSH) (IU/l) according to our laboratory standard. Premenopausal, estradiol $\geq 0.12$ FSH $\leq 30$; Perimenopausal, estradiol $\geq 0.12$ FSH $>30$; Postmenopausal, estradiol $<0.12$ FSH $>20$.

with $\mathrm{D}$-score $<0$ are associated with a high risk of coexistent or future EC (22-24). In the original computerized morphometric analysis study on $\mathrm{EH}$, a total of 10 nuclear features and 12 architectural features were analyzed (25). Using a linear stepwise regression analysis and discriminant analysis, three of these quantitative features were selected as having significant independent prognostic value and were combined into the formula called Dscore, as follows: $\mathrm{D}$-score $=0.6229+0.0439 \mathrm{x}$ (volume percentage stroma) - 3.9934x Ln (standard deviation of shortest nuclear axis) - 0.1592x (outer surface density glands), where Ln stands for natural logarithm (25). The measurements were performed with a Q-PRODIT image analysis system (version 6.1; Leica, Cambridge, UK). The method of the D-score analysis has been described in detail in former studies (22-24).
Table II. Distribution of histological WHO94 diagnosis and D-score categories in baseline biopsies.

\begin{tabular}{lccc}
\hline $\begin{array}{l}\text { WHO94 diagnosis/ } \\
\text { therapy group }\end{array}$ & $\begin{array}{c}\mathrm{n}=33 \\
\mathrm{D} \text {-score } \geq 0\end{array}$ & $\begin{array}{c}\mathrm{n}=4 \\
\mathrm{D} \text {-score }<0\end{array}$ & Total \\
\hline SH & 14 & 0 & 14 \\
CH & 19 & 1 & 20 \\
AH & 0 & 3 & 3 \\
& 33 & 4 & 37 \\
\hline
\end{tabular}

Patients with D-score $\geq 0$ were included in therapy group A and patients with D-score $<0$ were included in therapy group B. SH: Simple hyperplasia; $\mathrm{CH}$ : complex hyperplasia; $\mathrm{AH}$ : atypical hyperplasia.

Ethical considerations. The current study was approved by the Regional Committees for Medical and Health Research Ethics (2015/381) and by the Norwegian Medicines Agency (EUDRACT number 2015-000612-17). All participants gave written informed consent. Insurance for the coverage of pharmaceutical injuries was signed for all study participants.

Statistics. Descriptive statistics was performed using IMB SPSS Statistics version 24 (IMB, Armonk, NY, USA).

\section{Results}

Patients. A total of 38 women were consecutively assigned to therapy group $A(n=34)$ and therapy group $B(n=4)$. One patient in therapy group A experienced expulsion of low-dose LNG-IUS after 13 weeks of therapy owing to excessive vaginal bleeding (Figure 1). Clinical and demographic data of the women completing the study $(n=37)$ are summarized in Table I. Median age at diagnosis was 51 years (range $=30-84$ years). Median BMI (body mass index, $\mathrm{kg} / \mathrm{m}^{2}$ ) was 27.7 (range=20.140.6). Altogether, $78.3 \%$ of the women were overweight (BMI 25-29.9) or obese (BMI $\geq 30$ ). Classification of hyperplastic areas (within endometrial polyps or fragments of polyps), according to WHO94 and D-score, in baseline biopsies are presented in Table II. Among women with D-score $\geq 0$, none was diagnosed with $\mathrm{AH}$. However, three out of four women with D-score $<0$ were diagnosed with $\mathrm{AH}$ and none had $\mathrm{SH}$.

Response to therapy. All women $(n=33)$ in therapy group A obtained complete response after six months of therapy with the LNG-IUS Jaydess. Thus, post-therapy biopsies displayed no sign of hyperplastic areas, and only inactive or sparse atrophic endometrial glands as well as pseudodecidualized endometrial stroma were observed by light microscopy (Figure 2A-B). Nevertheless, small fragments of endometrial polyps were evident in the post-therapy biopsy of five women. The majority of women in therapy group A $(n=31)$ preferred to keep the LNG-IUS in situ after completing the study. Only one out of four women in therapy group B responded to therapy according to histopathological investigation of the hysterectomy specimen. The baseline biopsy diagnosis of the responding woman was 


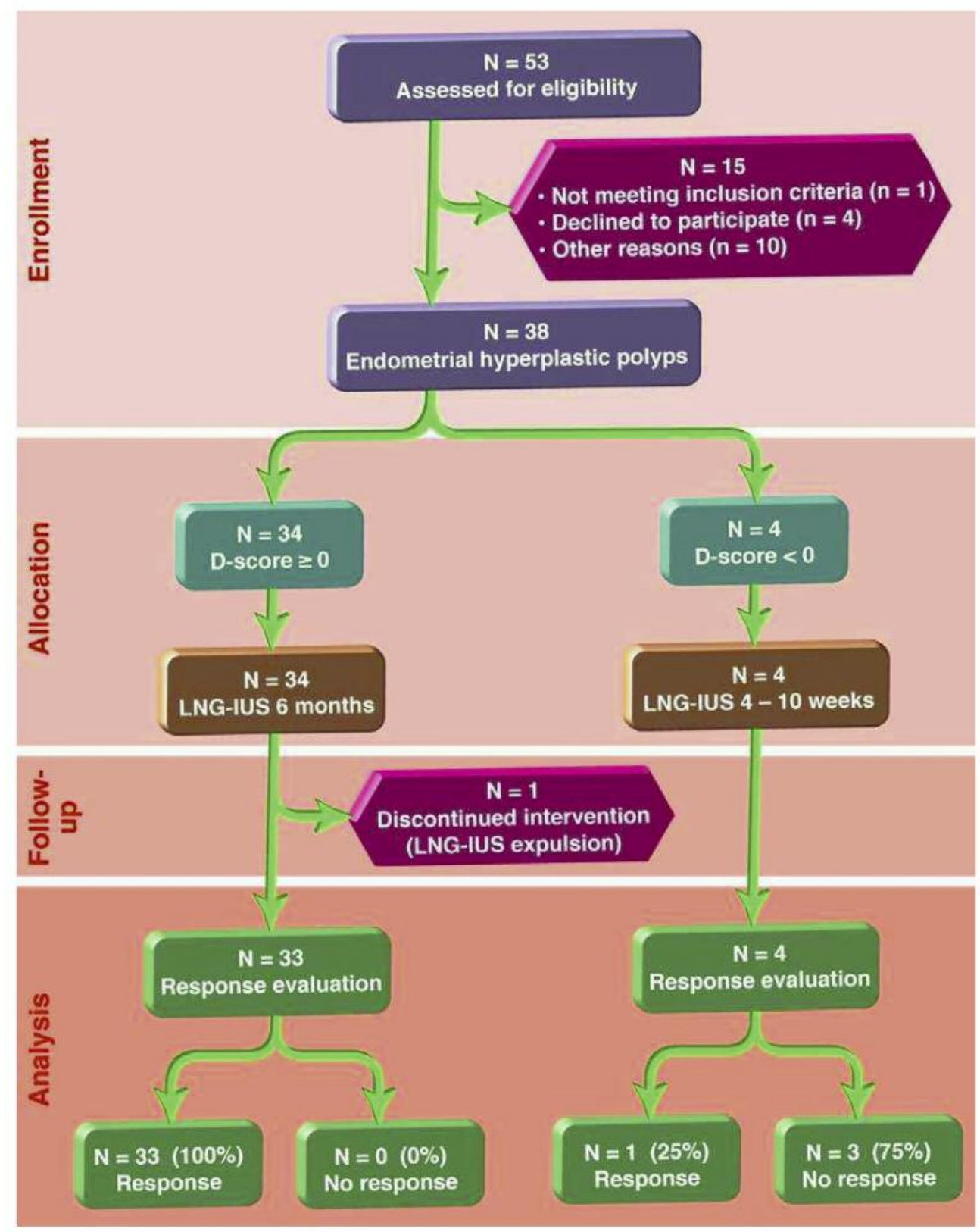

Figure 1. Flow chart showing enrollment, allocation, follow-up and analysis. Therapy response was defined as endometrium with progestin effect (atrophic glands and pseudodecidualized stroma).

$\mathrm{CH} / \mathrm{D}$-score -0.4 , and therapy duration for LNG-IUS Jaydess prior to hysterectomy was seven weeks. The other three women (who did not respond to therapy) were diagnosed with $\mathrm{AH}$ according to baseline biopsy, and therapy duration was four, five and 10 weeks, respectively. Although hyperplastic changes were still evident in the hysterectomy specimens of these three women, microscopy revealed typical progestin-induced changes with stromal pseudodecidualization and no sign of cytological atypia after 10 weeks of therapy (Figure 2C-D). Endometrial polyps were seen in the hysterectomy specimen of the women treated for five weeks. None of the included women were diagnosed with EC during the study.

Adverse events. No serious adverse events occurred during the study period. Adverse events reported were vaginal bleeding, headache, and mild abdominal pain (Table III). Bleeding disturbances were most prominent during the first three months of therapy, and it persisted in only two women after six months of therapy. The two women reporting headache had sparse and short-lived symptoms. Two women decided to 

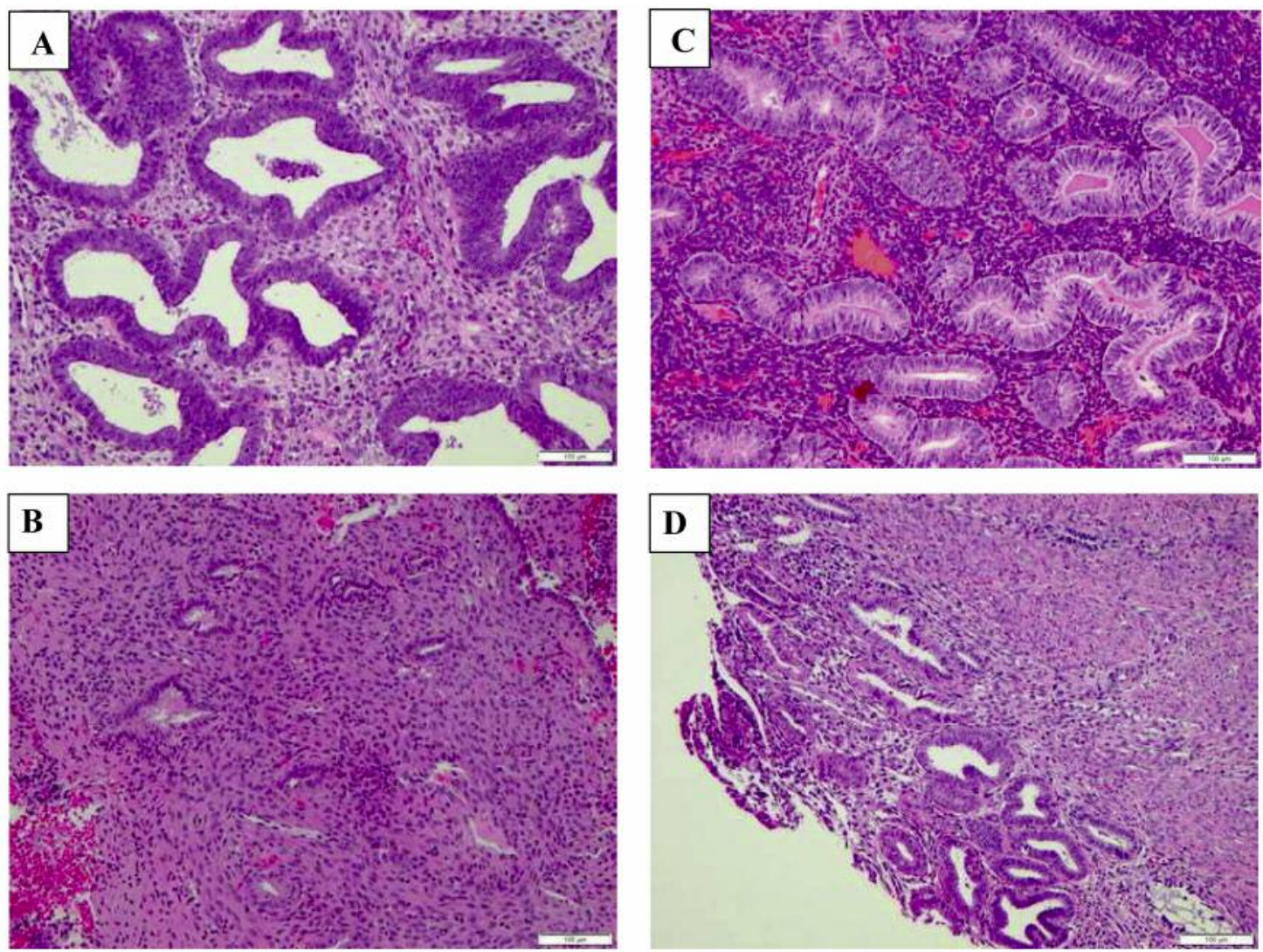

Figure 2. Microphotographs of histological specimens from endometrial biopsies taken before (baseline biopsy) and after (post-therapy biopsy) therapy with the LNG-IUS Jaydess (hematoxylin and eosin, 20x magnification). (A) Baseline biopsy. Fragments of an endometrial polyp containing hyperplastic areas classified as complex hyperplasia. The Dscore value was 1.4. (B) Post-therapy biopsy after six months treatment showed complete therapy response characterized by extensive glandular atrophy and pseudodecidualized stroma. No endometrial polyps or fragments of polyps were seen. (C) Baseline biopsy. An area with tightly packed glands within a hyperplastic endometrial polyp is seen. The hyperplastic areas were classified as atypical and the D-score value was -0.5. (D) Post-therapy biopsy (hysterectomy specimen) after 10 weeks treatment. Only one single superficial focus of complex hyperplasia was found in the endometrium of the hysterectomy specimen. The remaining endometrium revealed complete therapy response. No endometrial polyps or fragments of polyps were seen.

remove the LNG-IUS after six months therapy due to vaginal bleeding $(\mathrm{n}=1)$ and recurrent urinary infections $(\mathrm{n}=1)$.

\section{Discussion}

Our pilot study is, to our knowledge, the first ever to investigate the efficacy of low-dose LNG-IUS $13.5 \mathrm{mg}$ as a therapeutic option for EHP. The demonstrated therapy response for all the women with low- to medium-risk EHP in our study corresponds to the results described by Arnes et al. reporting 100\% regression for high-dose LNG-IUS $52 \mathrm{mg}$ in women with EHP, independent of risk group, after six months of therapy (15).

In contrast, only one among four women with EHP showing high-risk hyperplasia responded to therapy after 410 weeks in the current study. A higher dose requirement for atypical lesions may be of importance although the shorter treatment time offered to these women may also be a crucial
Table III. Adverse events during therapy with LNG-IUS Jaydess.

\begin{tabular}{lcc}
\hline Symptoms/Grading of adverse effects & Grade 1 & Grade 2 \\
\hline Vaginal bleeding & 6 & 10 \\
Headache & 2 & 0 \\
Abdominal pain & 0 & 1 \\
\hline
\end{tabular}

Grade 1 means adverse event $\leq 10$ days/month, grade 2 means adverse event $>10$ days/month.

point. Ideally, the women with high-risk EHP should have received LNG- IUS therapy for a longer period of time to allow adequate evaluation of therapy response.

However, ethical considerations prevented conservative management for these women as low- dose LNG-IUS had never before been explored as therapy for EHP. 
In the present study we hypothesized that hyperplastic foci within EP had the same risk of malignant progression as EH and that these hyperplastic foci would respond to progestin therapy in a similar manner as observed for nonpolypoid $\mathrm{EH}$ $(10,17,26)$. Risk-stratification of $\mathrm{EH}$ by $\mathrm{D}$-score analysis have been successfully used for years in our clinic and in a recent retrospective study with long-term follow-up, these methods were reported to be applicable as predictors of malignant transformation in EHP as well (15).

As hyperplasia within an EP has been demonstrated to be a strong marker of wider endometrial pathology, our results support the rationale behind intrauterine progestin therapy for these women. Kelly et al. have found hyperplasia in the surrounding endometrium in more than half of the women with EHP (5). Another study reported that over $90 \%$ of women demonstrated residual hyperplasia in the hysterectomy specimen, despite normal hysteroscopic view, after removal of EP containing complex atypical hyperplasia (6). The authors concluded that hysteroscopic evaluation of the uterine cavity and polyp resection are insufficient for eradication of premalignant and malignant endometrial lesions (6). On this background, the ability of intrauterine progestin therapy to induce strong antiproliferative effect throughout the entire endometrial mucosa is considered advantageous over hysteroscopic resection of such lesions alone.

Previous research on EP has mainly focused on the malignant potential in macroscopically visible polyps available for resection by hysteroscopy. In contrast, the present study was designed to assess if progestin therapy is effective treatment in women with EHP diagnosed by microscopy. Small EP have shown to be frequently overlooked by vaginal ultrasonography and hysteroscopy, and incidental discovery of EP, with and without hyperplastic areas during routine histopathological examination of endometrial biopsy specimens, is common $(15,27)$. Correspondingly, EP was suspected by vaginal ultrasonography in only nine out of 37 women in the present study population.

In the current study we defined therapy response as complete clearance of hyperplastic glands, but presence or absence of polyp tissue in post-therapy biopsies was also of interest. In therapy group A, only five women had fragments of polyps in post-therapy biopsies but no evidence of hyperplastic areas. These women kept the low-dose LNGIUS in situ and underwent additional endometrial sampling outside the study protocol 12 months after LNG-IUS insertion. The following microscopical investigation of biopsy material demonstrated sustained progestin effect and no signs of EP or fragments of polyps. Thus, low-dose LNGIUS seems capable to induce regression of both hyperplastic areas within EP, and EP without hyperplasia.

None of our study participants reported persisting systemic side-effects, and the therapy was generally well tolerated throughout the treatment period, making the low- dose LNG-IUS optimal for long-term use. Recurrence rate after hysteroscopic resection of EP is high (13.3\%) and hyperplastic EP recurs more frequently than benign ones (43.6\%) (28). Even though relapse during long-term follow up was not investigated in the current study, favorable clinical effect to prevent recurrence of $\mathrm{EH}$ by long-term LNG-IUS therapy has been observed by others (29).

To conclude, we demonstrated encouraging therapy responses for low- to medium-risk EHP after six months therapy with low-dose LNG-IUS. Whether or not the progestin dose provided by this IUS is too low to induce regression of high-risk EHP, or if therapy response could have been achieved by extending therapy duration, still remains unclear. Such studies should be addressed by future research with larger study populations.

\section{Conflicts of Interest}

There are no conflicts of interest regarding this study.

\section{Authors' Contributions}

Elise Thoresen Sletten is the main author of the manuscript, performed the clinical patient work and statistical analysis of patient data. Marit Arnes contributed to the microscopical work and data analyses. Anne Beate Vereide facilitated recruitment of patients. Anne Ørbo is the project leader and supervisor and performed all the microscopical work.

\section{Acknowledgements}

The Authors would like to thank participating gynecological outpatient clinics in northern Norway (Troms $\varnothing$, Harstad, Stomarknes, Kirkenes, Finnsnes, Alta, Hammerfest), Lena M. M. Lyså, B.Sc., and Bjørn T.G. Moe, M.Sc., for skilled image analyses performed on endometrial biopsy material, and Roy A. Lyså, Ph.d. for figure artwork.

\section{References}

1 Clark TJ and Stevenson H: Endometrial Polyps and Abnormal Uterine Bleeding (AUB-P): What is the relationship, how are they diagnosed and how are they treated? Best Pract Res Clin Obstet Gynaecol 40: 89-104, 2017. PMID: 27914969. DOI: 10.1016/j.bpobgyn.2016.09.005

2 Lieng M, Istre $\mathrm{O}$ and Qvigstad E: Treatment of endometrial polyps: a systematic review. Acta Obstet Gynecol Scand 89: 992-1002, 2010. PMID: 20528202. DOI: 10.3109/00016 349.2010.493196

3 Lee SC, Kaunitz AM, Sanchez-Ramos L and Rhatigan RM: The oncogenic potential of endometrial polyps: a systematic review and meta-analysis. Obstet Gynecol 116: 1197-1205, 2010. PMID: 20966706. DOI: 10.1097/AOG.0b013e3181f74864

4 Ricciardi E, Vecchione A, Marci R, Schimberni M, Frega A, Maniglio P, Caserta D and Moscarini M: Clinical factors and malignancy in endometrial polyps. Analysis of 1027 cases. Eur J Obstet Gynecol Reprod Biol 183: 121-124, 2014. PMID: 25461364. DOI: 10.1016/j.ejogrb.2014.10.021

5 Kelly P, Dobbs SP and McCluggage WG: Endometrial hyperplasia involving endometrial polyps: report of a series and discussion of the significance in an endometrial biopsy 
specimen. BJOG 114: 944-950, 2007. PMID: 17565613. DOI: 10.1111/j.1471-0528.2007.01391.x

6 Elyashiv O, Sagiv R, Kerner R, Keidar R, Menczer J and Levy $\mathrm{T}$ : Hysterscopic resection of premalignant and malignant endometrial polyps: Is it a safe alternative to hysterectomy? J Minim Invasive Gynecol 24: 1200-1203, 2017. PMID: 28802955. DOI: $10.1016 /$ j.jmig.2017.08.002

7 Kurman RJ, Kaminski PF and Norris HJ: The behavior of endometrial hyperplasia. A long-term study of "untreated" hyperplasia in 170 patients. Cancer 56: 403-412, 1985. PMID: 4005805. DOI: $10.1002 / 1097-0142(19850715) 56: 2<403::$ aidcncr2820560233>3.0.co;2-x

8 Perino A, Quartararo P, Catinella E, Genova G and Cittadini E: Treatment of endometrial hyperplasia with levonorgestrel releasing intrauterine devices. Acta Eur Fertil 18: 137-140, 1987. PMID: 3115027.

9 Clark TJ, Neelakantan D and Gupta JK: The management of endometrial hyperplasia: an evaluation of current practice. Eur J Obstet Gynecol Reprod Biol 125: 259-264, 2006. PMID: 16246481. DOI: 10.1016/j.ejogrb.2005.09.004

10 Orbo A, Vereide AB, Arnes M, Pettersen I and Straume B: Levonorgestrel-impregnated intrauterine device as treatment for endometrial hyperplasia: a national multicentre randomised trial. BJOG 121: 477-486, 2014. PMID: 24286192. DOI: 10.1111/ 1471-0528.12499

11 Abu Hashim H, Ghayaty E and El Rakhawy M: Levonorgestrelreleasing intrauterine system vs oral progestins for non-atypical endometrial hyperplasia: a systematic review and metaanalysis of randomized trials. Am J Obstet Gynecol 213: 469-478, 2015. PMID: 25797236. DOI: 10.1016/j.ajog.2015.03.037

12 American Association of Gynecologic Laparoscopists: AAGL practice report: practice guidelines for the diagnosis and management of endometrial polyps. J Minim Invasive Gynecol 19: 3-10, 2012. PMID: 22196255. DOI: 10.1016/j.jmig. 2011.09.003

13 van Dijk MM, van Hanegem N, de Lange ME and Timmermans A: Treatment of women with an endometrial polyp and heavy menstrual bleeding: A levonorgestrel-releasing intrauterine device or hysteroscopic polypectomy? J Minim Invasive Gynecol 22: 11531162, 2015. PMID: 26151760. DOI: 10.1016/ j.jmig.2015.06.016

14 Dominick S, Hickey M, Chin J and Su HI: Levonorgestrel intrauterine system for endometrial protection in women with breast cancer on adjuvant tamoxifen. Cochrane Database Syst Rev (12): CD007245, 2015. DOI: 10.1002/14651858.CD007 245.pub3

15 Arnes M, Hvingel B and Orbo A: Levonorgestrel-impregnated Intrauterine device reduces occurrence of hyperplastic polyps: a population-based follow-up cohort study. Anticancer Res 34: 2319-2324, 2014. PMID: 24778038.

16 Janssens D, Verbeeck G and Wildemeersch D: Use of a frameless LNG-IUS as conservative treatment for a pre-malignant uterine polyp in a premenopausal woman - a case report. Facts Views Vis Obgyn 7: 257-260, 2015. PMID: 27729971.

17 Sletten ET, Arnes M, Vereide AB and Orbo A: Low-dose LNGIUS as therapy for endometrial hyperplasia. a prospective cohort pilot study. Anticancer Res 38: 2883-2889, 2018. PMID: 29715 112. DOI: 10.21873 /anticanres. 12534

18 Nelson A, Apter D, Hauck B, Schmelter T, Rybowski S, Rosen $\mathrm{K}$ and Gemzell-Danielsson K: Two low-dose levonorgestrel intrauterine contraceptive systems: a randomized controlled trial. Obstet Gynecol 122: 1205-1213, 2013. PMID: 24240244. DOI: 10.1097/AOG.0000000000000019
19 Apter D, Gemzell-Danielsson K, Hauck B, Rosen K and Zurth C: Pharmacokinetics of two low-dose levonorgestrel-releasing intrauterine systems and effects on ovulation rate and cervical function: pooled analyses of phase II and III studies. Fertil Steril 101: 1656-1662, 2014. PMID: 24726226. DOI: 10.1016/ j.fertnstert.2014.03.004

20 Kim KR, Peng R, Ro JY and Robboy SJ: A diagnostically useful histopathologic feature of endometrial polyp: the long axis of endometrial glands arranged parallel to surface epithelium. Am J Surg Pathol 28: 1057-1062, 2004. PMID: 15252313.

21 Gallos ID, Krishan P, Shehmar M, Ganesan R and Gupta JK: Relapse of endometrial hyperplasia after conservative treatment: a cohort study with long-term follow-up. Hum Reprod 28: 12311236, 2013. PMID: 23466671. DOI: 10.1093/humrep/det049

22 Baak JP, Orbo A, van Diest PJ, Jiwa M, de Bruin P, Broeckaert M, Snijders W, Boodt PJ, Fons G, Burger C, Verheijen RH, Houben PW, The HS and Kenemans P: Prospective multicenter evaluation of the morphometric D-score for prediction of the outcome of endometrial hyperplasias. Am J Surg Pathol 25: 930935, 2001. PMID: 11420465 .

23 Orbo A, Baak JP, Kleivan I, Lysne S, Prytz PS, Broeckaert MA, Slappendel A and Tichelaar HJ: Computerised morphometrical analysis in endometrial hyperplasia for the prediction of cancer development. A long-term retrospective study from northern Norway. J Clin Pathol 53: 697-703, 2000. PMID: 11041060. DOI: $10.1136 /$ jcp.53.9.697

24 Orbo A, Kaino T, Arnes M, Larsen K, Pettersen I and Moe B: Prognostic markers for coexistent carcinoma in high-risk endometrial hyperplasia with negative D-score: significance of morphometry, hormone receptors and apoptosis for outcome prediction. Acta Obstet Gynecol Scand 88: 1234-1242, 2009. PMID: 19900140. DOI: 10.3109/00016340903281014

25 Baak JP, Nauta JJ, Wisse-Brekelmans EC and Bezemer PD: Architectural and nuclear morphometrical features together are more important prognosticators in endometrial hyperplasias than nuclear morphometrical features alone. J Pathol 154: 335-341, 1988. PMID: 3385513. DOI: 10.1002/path.1711540409

26 Gallos ID, Shehmar M, Thangaratinam S, Papapostolou TK, Coomarasamy A and Gupta JK: Oral progestogens vs. levonorgestrel-releasing intrauterine system for endometrial hyperplasia: a systematic review and metaanalysis. Am J Obstet Gynecol 203: 547.e1-e10, 2010. PMID: 20934679. DOI: 10.1016/j.ajog.2010.07.037

27 Exalto N, Stappers C, van Raamsdonk LA and Emanuel MH: Gel instillation sonohysterography: first experience with a new technique. Fertil Steril 87: 152-155, 2007. PMID: 17097650. DOI: $10.1016 /$ j.fertnstert.2006.05.075

28 Paradisi R, Rossi S, Scifo MC, Dall'O F, Battaglia C and Venturoli S: Recurrence of endometrial polyps. Gynecol Obstet Invest 78: 26-32, 2014. PMID: 24862037. DOI: 10.1159/0003 62646

29 Orbo A, Arnes M, Hancke C, Vereide AB, Pettersen I and Larsen K: Treatment results of endometrial hyperplasia after prospective Dscore classification: a follow-up study comparing effect of LNG-IUD and oral progestins versus observation only. Gynecol Oncol 111: 6873, 2008. PMID: 18684496. DOI: 10.1016/ j.ygyno.2008.06.014

Received June 27, 2019

Revised July 20, 2019

Accepted July 22, 2019 